\title{
АНАЛИЗ ИНДУКЦИИ АПОПТОЗА ЛИМФОЦИТОВ ПЕРИФЕРИЧЕСКОЙ КРОВИ ЧЕЛОВЕКА СВЕРХИНТЕНСИВНЫМ ГАММА-ИЗЛУЧЕНИЕМ IN VITRO
}

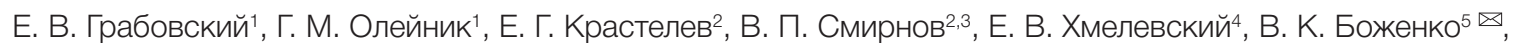
А. М. Шишкин ${ }^{5}$ А. В. Иванов ${ }^{5}$, Т. М. Кулинич

${ }^{1}$ Троицкий институт инновационных и термоядерных исследований (ТРИНИТИ),

ГК «Росатом», Троицк, Москва

2 Объединенный институт высоких температур РАН, Москва

${ }^{3}$ Научно исследовательский институт технической физики и автоматизации,

ГК «Росатом», Москва

${ }^{4}$ Московский научно-исследовательский онкологический институт имени П. А. Герцена - филиал Национального медицинского исследовательского центра радиологии, Москва

${ }^{5}$ Российский научный центр рентгенорадиологии, Москва

Относительная биологическая эффективность ионизирующего излучения определяется рядом параметров, одним из которых является мощность дозы. В терапевтических лучевых установках используется облучение с мощностью дозы до нескольких Гр/мин. Эффект высоких и особенно сверхвысоких (10 Гр/мин и выше) мощностей дозы практически не изучен. Целью нашего исследования являлось определение влияния гамма-излучения, имеющего сверхвысокую мощность дозы, на индукцию апоптоза в лимфоцитах периферической крови человека. Лимфоциты получали из крови условно здоровых добровольцев выделением их на градиенте плотности. Образцы суспензии лимфоцитов при низкой мощности дозы облучали на установке «Рокус-АМ» (Россия), при мощности дозы около $10^{8}$ Гр/с - на экспериментальных установках «Ангара-5-1» и «Мир-М» (Россия). Уровень апоптоза регистрировали методом проточной цитофлуориметрии с двойной окраской аннексином $\mathrm{V}$ и йодидом пропидия. Установили, что гамма-излучение со сверхвысокой мощностью дозы в диапазоне доз 1-6 Гр индуцирует апоптоз в лимфоцитах периферической крови достоверно выше, чем гамма-излучение с низкой мощностью дозы ( $p<0,05)$, одновременно в меньшей степени индуцируя некроз. При этом общий уровень радиационной гибели лимфоцитов для терапетивческой и экспериментальных установок достоверно не различался. Дальнейшие исследования позволят уточнить биологическую и медицинскую значимость полученных результатов.

Ключевые слова: сверхинтенсивное гамма-излучение, сверхинтенсивное рентгеновское излучение, мощность дозы, клеточная гибель, апоптоз, некроз, лимфоциты

Финансирование: работа выполнена при поддержке ГК «Росатом» и Российского научного фонда (грант № 15-10355).

$\triangle$ Для корреспонденции: Боженко Владимир Константинович ул. Профсоюзная, д. 86, г. Москва, 117997; vbojenko@mail.ru

Статья получена: 22.11.2017 Статья принята к печати: 05.12.2017

\section{ANALYSIS OF THE APOPTOTIC EFFECT OF ULTRAHIGH GAMMA DOSE RATES ON HUMAN PERIPHERAL BLOOD LYMPHOCYTES IN VITRO}

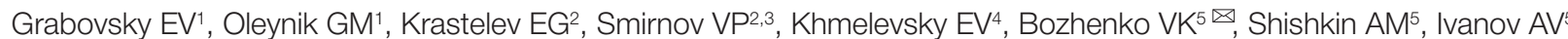 \\ Kulinich TM ${ }^{5}$ \\ ${ }^{1}$ Troitsk Institute for Innovation and Fusion Research (TRINITI), \\ Rosatom State Atomic Energy Corporation, Troitsk, Moscow, Russia \\ 2 Joint Institute for High Temperatures, Russian Academy of Sciences, Moscow, Russia \\ ${ }^{3}$ Research Institute of Technical Physics and Automation, \\ Rosatom State Atomic Energy Corporation, Moscow, Russia \\ ${ }^{4}$ Hertzen Moscow Cancer Research Institute (affiliated branch of the National Medical Research Radiology Center), Moscow, Russia \\ ${ }^{5}$ Russian Scientific Center of Roentgenoradiology, Moscow, Russia
}

Relative biological effectiveness of ionizing radiation is determined by a number of factors, including a dose rate. Radiotherapy equipment employs low dose rates of up to a few Gy per minute. But very little is known about the biological effect of high and ultrahigh ( $\geq 10^{8} \mathrm{~Gy} / \mathrm{min}$ ) dose rate radiation. Our study aimed to investigate the apoptotic effect of ultrahigh gamma dose rates on human peripheral blood lymphocytes. Blood samples were collected from seemingly healthy donors. Lymphocytes were isolated by density gradient separation. Lymphocyte suspensions were irradiated with low-rate doses on the RokusAM gamma-ray machine for clinical use (Russia) and with $10^{8} \mathrm{~Gy} / \mathrm{s}$ doses on the experimental pulse generators Angara-5-1 and Mir-M (Russia). Apoptosis was measured by flow cytometry using annexin $\mathrm{V}$ and propidium iodide double staining. We established that in comparison with low dose rates, ultrahigh gamma dose rates (with doses ranging from 1 to 6 Gy) induced significantly more pronounced apoptosis in peripheral blood lymphocytes $(p<0.05)$ with fewer necrotic cells. Total radiationinduced cell death did not differ significantly between the therapeutic gamma machine and the experimental pulse generators. Further research is needed to assess biological and medical significance of our findings.

Keywords: ultrahigh dose rate gamma radiation, ultrahigh intensity X-rays, dose rate, cell death, apoptosis, necrosis, lymphocytes

Funding: this work was supported by Rosatom and the Russian Science Foundation (Grant no. 15-10355).

Correspondence should be addressed: Vladimir Bozhenko

ul. Profsoyuznaya, d. 86, Moscow, Russia, 117997; vbojenko@mail.ru

Received: 22.11.2017 Accepted: 05.12.2017 
Действенность радиологических методов лечения злокачественных опухолей основана на ряде биологических эфректов, в том числе гибели клеток вследствие лучевого воздействия. Ионизирующее излучение вызывает молекулярные повреждения в органеллах и компартментах клеток, наиболее опасными среди которых являются нарушения структуры ДНК. Их результатом является или гибель клеток, или репарация повреждений ДНК и восстановление нормального жизненного статуса клеток, или возникновение мутаций и индукция канцерогенеза, если изменения происходят в системе репарации ДНК [1].

Существует несколько типов гибели клеток под воздействием ионизирующего излучения [2, 3], из которых наибольший интерес в контексте радиотерапии представляет апоптоз - запрограммированная гибель клеток, усиливаемая излучением, не оказывающая при этом губительного воздействия на окружающие ткани и не вызывающая воспаления [4]. Некоторые типы клеток устойчивы к индуцируемому радиацией апоптозу, другие - могут изменять свою чувствительность в зависимости от стадии клеточного цикла и микроокружения [5]. В настоящее время ведется достаточно большое количество исследований по поиску путей контроля апоптотической активности некоторых типов клеток в ответ на радио- или химиотерапию злокачественных опухолей $[6,7]$.

Доказано, что многие противоопухолевые препарать способствуют росту апоптотической активности в новообразованиях, но не обладают избирательным действием и, следовательно, повреждают и нормальные ткани [8]. Недостатки лучевой терапии - образование некрозов в опухоли, а также губительное воздействие радиации на окружающие здоровые клетки. Имеются данные, что ионизирующее излучение стимулирует апоптоз тимоцитов, лимфоцитов, многих клеток-предшественников. Зрелые диффференцированные клетки редко уходят в апоптоз под действием излучения, но есть данные о вызванном радиацией апоптозе клеток молочной железы, кишечных крипт и миндалин у человека. В эксперименте был также индуцирован апоптоз мышиных яйцеклеток и клеток гепатоцеллюлярной карциномы [9].

Сильноточные импульсные ускорители электронов, работающие в режиме генерации высокоинтенсивного тормозного излучения, в настоящее время являются инструментами научных исследований, направленных на разработку новых радиационных технологий. В испытаниях были определены некоторые их недостатки, ограничивающие использование в медицине, например нестабильность параметров от импульса к импульсу. В то же время более узкий пучок излучения должен минимизировать влияние на окружающие ткани, а высокая интенсивность воздействия - увеличить повреждающий эффект на зону облучения [10]. Применяемые в клинической практике гамма-установки при терапевтической мощности дозы 1,5-2 Гр/мин обеспечивают поглощение клеткой размером 10 мкм в среднем 100 квантов/с с энергией около 1 МэВ. Паузы между актами лучевого воздействия составляют 1-10 мс, в то время как репарационные процессы в клетке идут быстрее и устраняют повреждения. Значительное увеличение интенсивности облучения, достижимое на современных сильноточных ускорителях пучков релятивистских электронов мощностью 1-100 ГВт, способно сократить время между актами облучения на 6-7 порядков, что должно (или может) привести к изменению реакции клетки на облучение. Опубликованные работы в области исследования влияния высокоинтенсивного радиационного излу- чения на биологические объекты противоречивы [11-15].

Целью исследования являлось определение биологических эффектов, вызываемых воздействием излучения высокой мощности экспериментальных установок «Ангара-5-1» и «Мир-М» на лимфоциты периферической крови человека, и их сравнение с эффектами, вызываемыми излучением низкой мощности терапевтической установки «Рокус-AM».

\section{МАТЕРИАЛЫ И МЕТОДЫ}

Исследование включало следующие этапы:

1) приготовление суспензии мононуклеарных клеток крови человека,

2) облучение полученных образцов с использованием терапевтического аппарата «Рокус-АМ» и установок высокоинтенсивного тормозного излучения «Ангара-5-1» и «Мир-М»,

3) определение в образцах доли клеток, вступивших в апоптоз, методом проточной цитофлуориметрии.

\section{Приготовление суспензии мононуклеарных клеток крови человека}

Использовали суспензии нормальных лимфоцитов, выделенных из крови условно здоровых доноров. Кровь, отобранную в объеме 2,6 мл в пробирки с натриевой солью ЭДТА в качестве антикоагулянта, разводили фосфатно-солевым бусером (ФСБ) в соотношении $1: 2$ и наслаивали на фиколл плотностью 1,077 («ПанЭко», Россия). Образцы центрифугировали в течение 40 мин при 400 g. Слой мононуклеаров, содержавший 70-90 \% лимфоцитов, отбирали с поверхности раздела, дважды отмывали ФСБ в течение 5 мин при $200 \mathrm{~g}$ и переводили в среду RPMl 1640, содержавшую 10 \% эмбриональной телячьей сыворотки.

Полученную суспензию мононуклеаров крови делили на аликвоты для последующего облучения. Всего каждый образец делили на 12 проб: 2 пробы являлись контрольными, необлученными, а 10 подвергали облучению 5 различными дозами, попарно. Далее облученные образцы инкубировали в $\mathrm{CO}_{2}$-инкубаторе при $37^{\circ} \mathrm{C}$ и 5 \% CO $\mathrm{CO}_{2}$. Для одного образца из каждой пары время инкубации составляло 24 ч, для другого - 48 ч. Выбранные временные интервалы позволяют объективно определить уровень радиоиндуцированного апоптоза. С момента получения крови и до помещения образцов в $\mathrm{CO}_{2}$-инкубатор все работы проводили при комнатной температуре в течение 3,5-4 ч.

\section{Облучение образцов на установке «Ангара-5-1»}

Источником высокоинтенсивного тормозного излучения в этой установке служат 8 независимых генераторов сверхвысокой электрической мощности [8]. Все модули срабатывают одновременно: среднеквадратичное отклонение по параметру составляет всего 10 нс. Максимальное напряжение на согласованной нагрузке - 1,5 мВ. Форма импульса напряжения представляет собой полусинусоиду с длительностью импульса на полувысоте амплитуды 40-70 нс. Анодом служит танталовая фольга толщиной 50 мкм (рис. 1).

Анализ спектрального состава тормозного излучения показал, что основная энергия квантов находится в диапазоне 200-600 кэВ. Анализ проводили по профилям сигналов алмазных рентгеновских дозиметров типа АДЗ (ВНИИА, Россия) с различными фильтрами. 
Непосредственно дозиметрию осуществляли термолюминесцентными дозиметрами (ТЛД) типа ДПГ-03 (НПП «Доза», Россия), в состав которого входят 3 поликристаллических детектора на основе бората магния. Величину дозы определяли прибором КДТ-О2М («Концерн-Электрон», Украина). По результатам прямой дозиметрии была экспериментально оценена зависимость дозы от расстояния объекта до диодов, на основании которой была рассчитана неоднородность дозы в зависимости от положения облучаемого образца. Расчеты показали, что на 1 см образца доза падает приблизительно на 10 \% в вертикальном направлении и на 9 \% - в горизонтальном относительно центра передней поверхности объекта. Были определены желательные места расположения образцов на фланце установки. Образцы помещали в цилиндрический дюралевый контейнер с толщиной дна и стенок 7 мм. Дно контейнера располагалось на расстоянии 57 мм от танталовой фольги.

Подведение различных доз к образцам достигалось расположением их на разном расстоянии от источников облучения. Максимальная доза варьировала от выстрела к выстрелу, поэтому рядом с образцами устанавливали дозиметры ТЛД. Одновременно с величиной дозы варьировала и ее мощность, т. к. продолжительность импульса при этом не менялась. При максимальной дозе (порядка 10 Гр) ее мощность превышала 100 МГр/с, при минимальной (менее 1 Гр) составляла около 10 МГр/с.

Для облучения образцы суспензии мононуклеаров помещали в пластиковые пробирки, располагаемые перпендикулярно относительно пучка излучения (рис. 2, В). Толщина слоя жидкости в пробирках составляла около 4 мм. После облучения образцы переносили в культуральные чашки и помещали в $\mathrm{CO}_{2}$-инкубатор, как было описано выше.

\section{Облучение образцов на установке «Мир-М»}

Установка «Мир-М» - экспериментальная установка, сильноточный наносекундный ускоритель электронов. Выходная энергия - до 800 кВ, длительность импульса 40-60 нс на полувысоте. Мишень анодного узла представляет собой танталовую фольгу толщиной 50-100 мКм.
Непосредственно за фольгой установлен дополнительный фильтр - углеродный композит Graflex толщиной 0,5-1 мм для поглощения прошедших через фольгу электронов. Фланец выпускного окна выполнен из алюминия толщиной 1 мм. Мощность доз совпадала с той, что получали при использовании установки «Ангара-5-1».

Дозиметрические измерения производили двумя способами.

Для оперативной дозиметрии использовали термолюминесцентные дозиметры ДТГ-4 (НПП «Доза»), представляющие собой монокристаллическую таблетку из фтористого лития, активированную магнием и титаном. Измерения облученных ТЛД производили на комплексе «ДОЗА-ТЛД» (НПП «Доза») с помощью программного обеспечения DVG того же производителя. Предел допустимой основной относительной погрешности системы ТЛДкомплекс «ДОЗА-ТЛД" (при доверительной вероятности $0,95)$ фотонного излучения составляет $\pm 30 \%$. Поэтому для повышения точности измерений дозиметры были дополнительно откалиброваны путем облучения на установке «Рокус-АМ» с источником излучения кобальт-60 в дозе 7 Гр с последующим измерением и учетом индивидуальных особенностей каждой таблетки ТЛД.

Для более точной дозиметрии использовали дозиметрические пленки Gafchromic EBT 2 (Ashland, США). Для обработки пленок использовали программу DoseLab 6.5 (Moebius Medical Systems, США). Ввиду того, что градиент дозы по оси пучка для установки «Мир-М» значителен и наблюдалось снижение дозы в 1,5-2 раза при прохождении 1 см объекта, в зависимости от используемого катода, при облучении стремились максимально уменьшить линейные размеры образца.

Образцы представляли собой 0,6 мл перемешанной суспензии мононуклеаров, герметизированной в гнезде диаметром 16 мм и глубиной 2 мм. Суспензия занимала весь объем гнезда, т. е. во время облучения лейкоциты были равномерно распределены в нем.

Пакет для облучения одного образца имел следующий состав: разделитель толщиной 5 мм из 2 пластиковых пластин толщиной 1 мм и промежутком между ними в 3 мм; слой пенополиуретана толщиной 2 мм с гнездом, содержащим образец; подложка в виде пластиковой

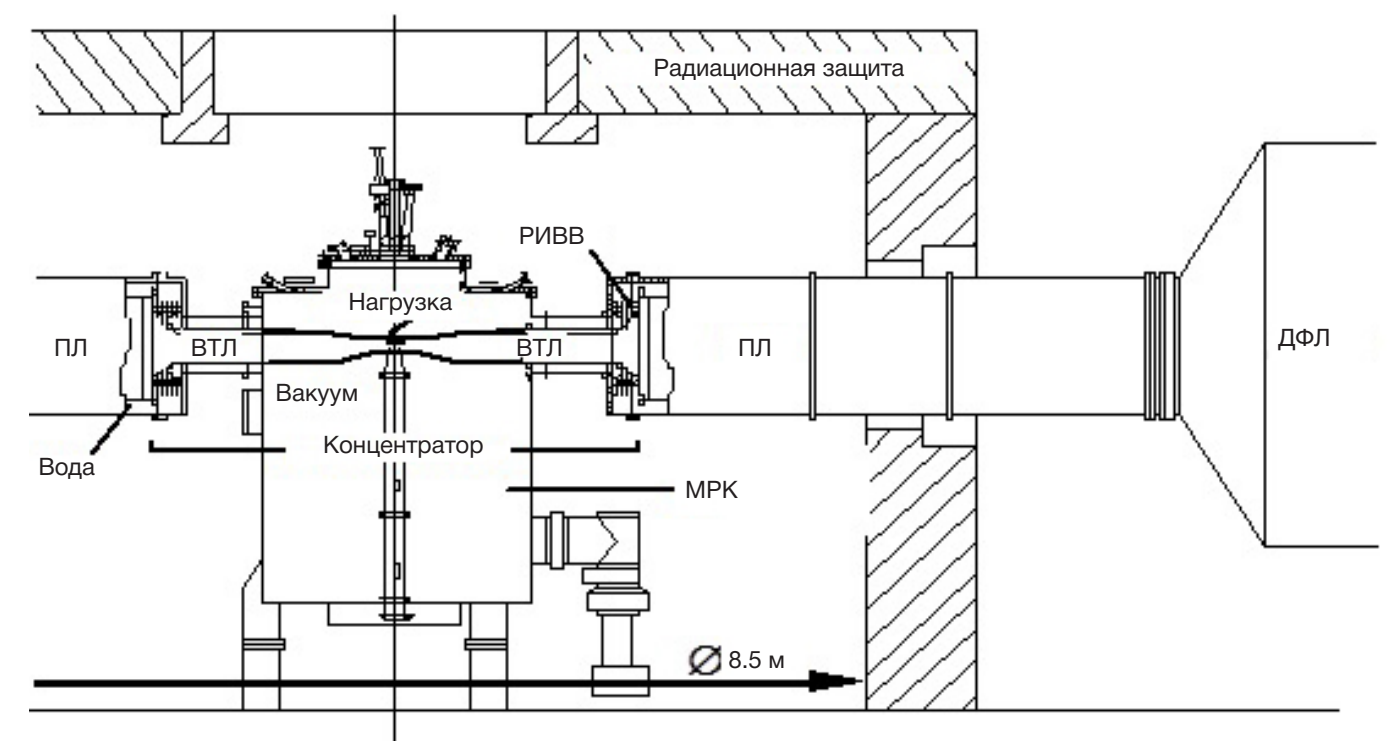

Рис. 1. Схема формирования и транспортировки электромагнитного импульса от модуля генератора установки «Ангара-5-1» к нагрузке, помещенной в вакуумную камеру. ДФЛ — водяная двойная формирующая линия; ПЛ — водяная передающая линия; РИВВ — разделительный изолятор интерфейса водавакуум; ВТЛ — вакуумная транспортирующая линия с магнитной самоизоляцией; MPK — вакуумная камера с концентратором электромагнитной мощности 
A

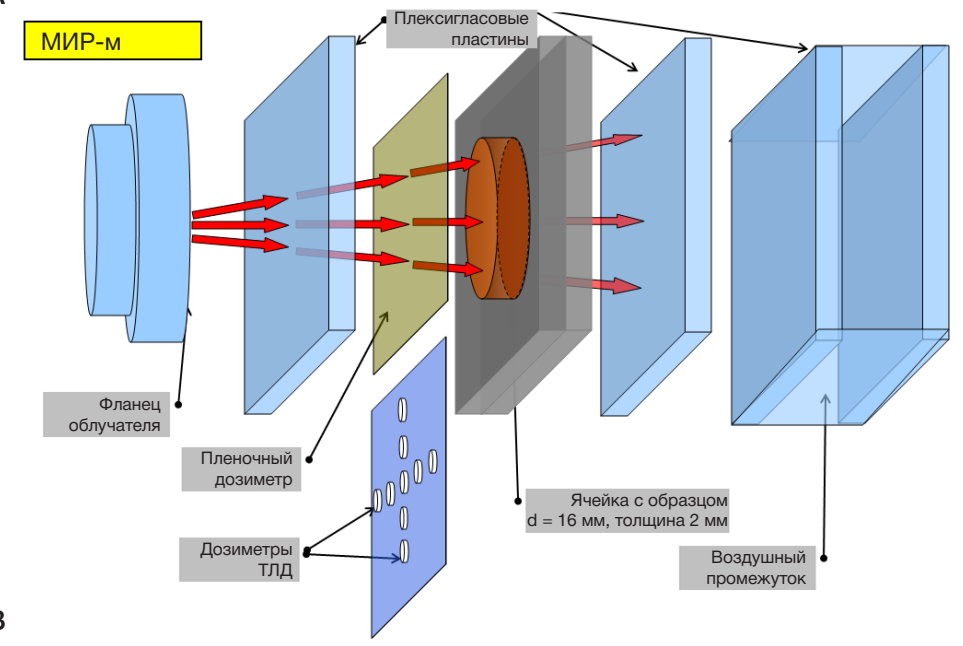

Б

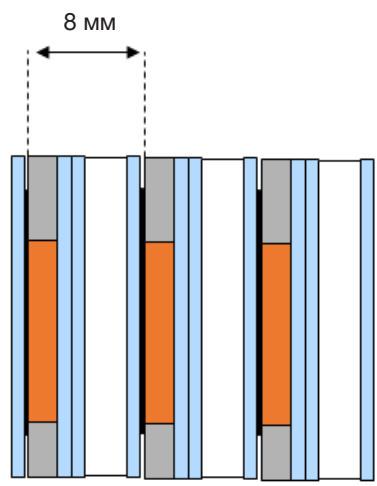

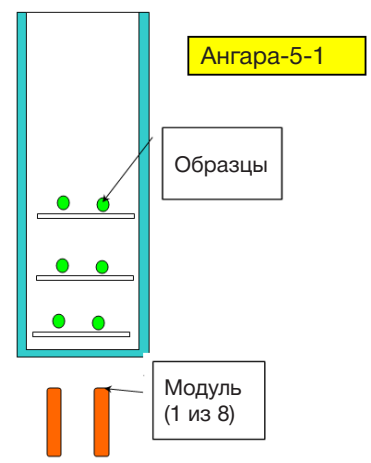

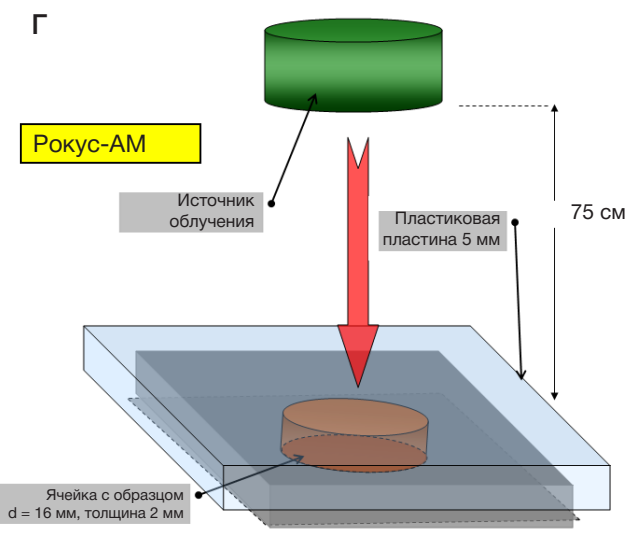

Рис. 2. Размещение образцов при облучении на установках «Мир-М» (А, Б), «Ангара-5-1» (В) и «Рокус-AМ» (Г)

пластины толщиной 1 мм. Пакеты размещались по одной оси так, что гнезда с образцами находились строго друг за другом. Таким образом, расстояние между образцами, если считать от центра, составило 8 мм. Расстояние от фрланца установки до фронтальной границы первого образца составило около 1 см. Дозиметры располагали после разделителя, прилегая непосредственно к передней поверхности гнезда с образцом (рис. 2, А, Б).

\section{Облучение образцов на терапевтической гамма- установке «Рокус-АМ»}

«Рокус-АМ» представляет собой терапевтическую гамма-установку. Источником излучения служит кобальт-60. В исследовании ее использовали для сравнения эффективности излучения малой мощности и высокоинтенсивного гамма-излучения. Мощность дозы применявшейся установки составляла 0,9 Гр/мин (15 МГр/с), т. е. в $10^{9}-10^{10}$ раз уступала мощности наносекундных ускорителей.

Для облучения использовали ту же клеточную суспензию, что и на установках высокоинтенсивного гамма-излучения. Это позволило нивелировать различия, связанные с индивидуальными особенностями образцов.

Облучение проводили в одиночном гнезде из набора, использованного при облучении на установке «Мир-М». Горизонтальное расположение образца позволило использовать открытый тонкостенный пластиковый контейнер, занимавший весь объем гнезда и имевший высоту стенок 2 мм (рис. 2, Г). В связи с необходимостью достижения расчетной дозы установления электронного равновесия в зоне образца сверху помещали пластиковую пластину толщиной 5 мм, а под образцом - плексигласовую пластину толщиной 15 мм.

Параметры облучения: расстояние источник-поверхность - 75 см, поле - $10 \times 10$ см. Облучение производили со смещением по времени в 1-1,5 ч относительно времени облучения на установках высокоинтенсивного гамма-излучения.

\section{Исследование уровня апоптоза в образцах}

По завершении инкубации исследовали уровень апоптоза в образцах клеточной суспензии методом проточной цитофлуориметрии. Использовали две методики: окраску нативных образцов с помощью набора Annexin V-FITC Kit (Beckman Coulter, CШA), содержащим аннексин V и йодид пропидия, и окраску фиксированных образцов йодидом пропидия.

В первом случае после облучения и инкубации образцы отмывали в ФСБ и проводили окрашивание 100 мкл клеточной суспезии, содержавшей $10^{6}$ клеток, согласно инструкции к набору Annexin V-FITC Kit. Данная методика окраски позволяет определить количество клеток, вступивших в апоптоз (аннексин V-положительные частицы); количество клеток, погибших/гибнущих по пути некроза (частицы, положительные по йодиду пропидия); оценить «ранний» апоптоз (частицы, положительные только по аннексину V) и «поздний» апоптоз (частицы, положительные и по аннексину $\mathrm{V}$, и по йодиду пропидия).

Окраска фиксированных образцов йодидом пропидия выявляет апоптоз в виде «субдиплоидного» пика на однопараметрической гистограмме и отражает количество апоптотических телец в образце. Фиксацию проводили в 70 \% 
ледяном этаноле после инкубации облученных образцов в течение 24 или 48 ч. Время фиксации составляло 72 ч. Далее клетки дважды отмывали в 1 мл ФСБ и ресуспендировали 100 мкл ФСБ. Для предотвращения связывания йодида пропидия с РНК исследуемую клеточную суспензию инкубировали с 20 мкл РНКазы A (R4875, Sigma-Aldrich, США) при $37^{\circ} \mathrm{C}$ в течение 30 мин. По окончании инкубации суспензию окрашивали 20 мкл йодида пропидия в течение 40 мин при комнатной температуре в защищенном от света месте. Перед анализом на проточном цитофлуориметре в образец вносили 1 мл ФСБ. Конечная концентрация клеток составляла не менее $10^{6}$ клеток.

Анализ проводили на проточном цитофлуориметре Cytomics FC 500 (Beckman Coulter). Измеряли отношение субдиплоидного пика к общему количеству клеток.

\section{РЕЗУЛЬТАТЫ ИССЛЕДОВАНИЯ}

При облучении лимфоцитов с помощью терапевтического гамма-аппарата «Рокус-АМ» установили, что зависимость уровня апоптоза от дозы облучения (в исследованном диапазоне доз) имеет линейный характер. При этом уровень апоптоза возрастает при увеличении времени инкубации после облучения: если через 24 ч инкубации уровень апоптоза под воздействием дозы в 5 Гр увеличивался примерно на 8,0 $\pm 2,2 \%$ относительно условного 0 \% в необлученных образцах, то через 48 ч инкубации наблюдалось увеличение уровня спонтанного апоптоза на 10,0 $\pm 2,6 \%$, а уровня апоптоза под воздействием дозы в 5 Гр - на $27,0 \pm 3,8 \%$ ( $p=0,004)$ (рис. 3).

При облучении лимфоцитов с помощью установки «Ангара-5-1» уровень апоптоза также имел линейную зависимость от дозы, однако наклон прямой был существенно выше по сравнению с наклоном прямой, построенной для результатов облучения на аппарате «Рокус-АМ» (рис. 3). Так, если при воздействии дозой в 3 Гр на «Рокус-АМ» уровень апоптоза через 48 ч инкубации составил 23,0 \pm 3,1 \%, то при воздействии высокоинтенсивным излучени- ем в дозе, сопоставимой с 3 Гр, уровень апоптоза в образце того же донора приближался к 31,0 \pm 3,8 \% ( $p=0,050)$. Таким образом, высокоинтенсивное тормозное излучение оказывает больший проапоптотический эффект, чем гамма-излучение в дозах «терапевтической» мощности.

Поскольку различия, полученные при сравнительном исследовании влияния излучения двух типов на индукцию апоптоза лимфоцитов периферической крови, оказались достоверными мы продолжили работу на экспериментальной установке «Мир-М», разработанной специально для проведения медико-биологических экспериментов, для более глубокого понимания влияния высокоинтенсивного излучения на индукцию апоптоза. Для этого использовали маркеры раннего и позднего апоптоза и выделили фрракцию некротических клеток, ранее не исследованную, т. к. эти клетки при регистрации субдиплоидного пика попадают во фрракцию неповрежденных клеток.

На рис. 4 показаны изменения уровня апоптоза (ранний - рис. 4, А и поздний - рис. 4, Б) и уровня некроза в облученных образцах (рис. 4, В), а также суммарная клеточная гибель (рис. 4, Г) в зависимости от дозы облучения и мощности установки. Провели сравнение воздействия гамма-излучения терапевтической установки «Рокус-АМ» и высокоинтенсивного излучения экспериментальной установки «Мир-М» (только для продолжительности инкубации образцов лимфоцитов в 48 ч).

Показано, что суммарная клеточная гибель примерно одинакова при работе с обеими установками, а при дозе облучения более 5 Гр наблюдается тенденция к увеличению клеточной гибели при облучении на установке «Рокус-АМ» (рис. 4, Г). Однако при сравнении типов клеточной гибели уровень апоптоза (количество аннексин V-положительных клеток) достоверно выше ( $p<0,05)$ при воздействии на периферические лимфоциты высокоинтенсивного излучения установки «Мир-М» в дозах от 4 Гр. Уровень некроза при воздействии установкой «Мир-М» не превышал $12,0 \pm 2,2 \%$ (доза 6 Гр), а при воздействии гамма-установкой «Рокус-АМ» - 44,0 \pm 8,1 \% (доза 6 Гр) $(\mathrm{p}=$ 0,0029).

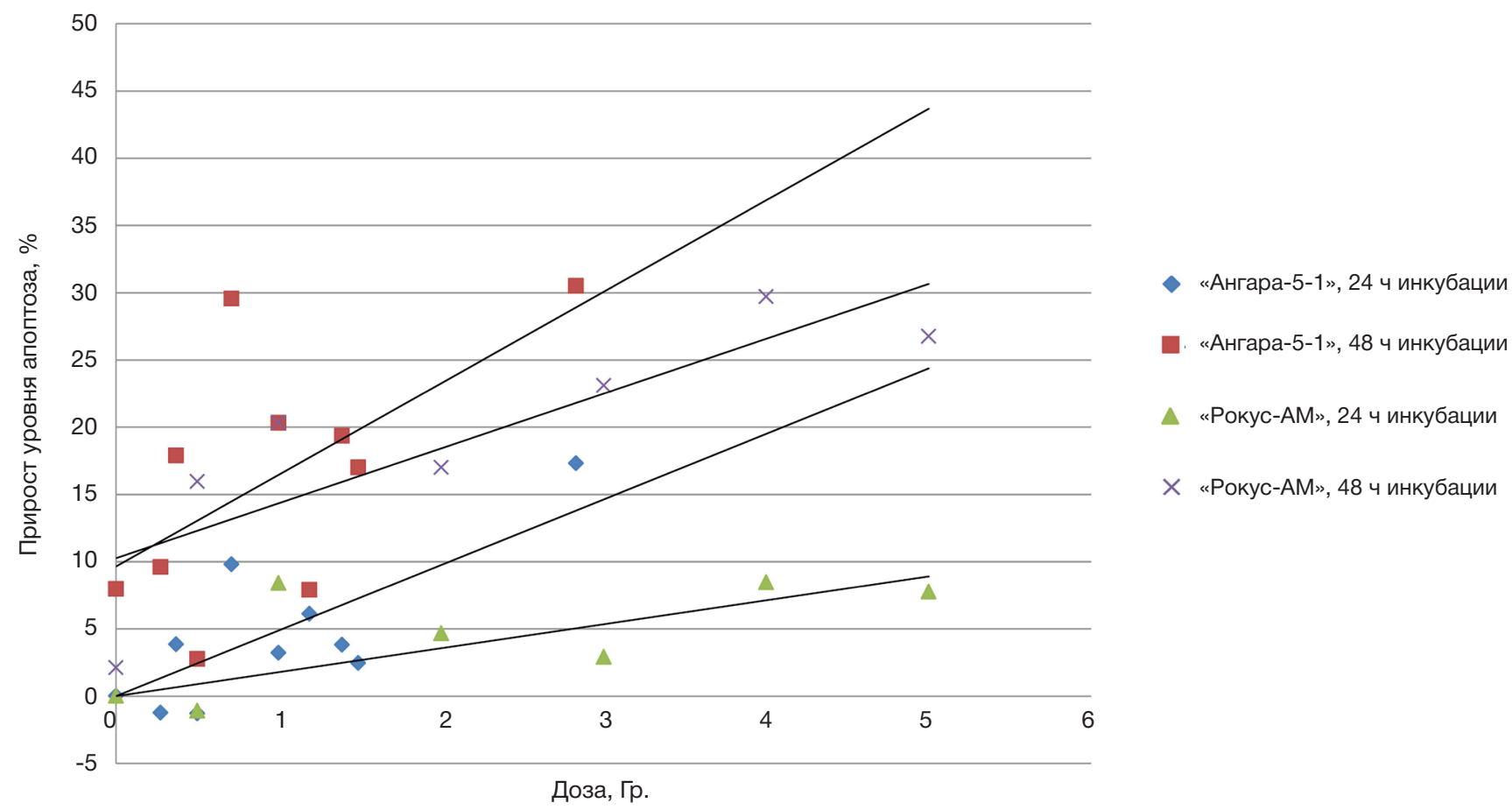

Рис. 3. Изменение уровня апоптоза при облучении образцов суспензии лимфоцитов периферической крови человека на установках «Рокус-АМ» и «Ангара-5-1» в дозах от 0 до 5 Гр 


\section{ОБСУЖДЕНИЕ РЕЗУЛЬТАТОВ}

В силу того, что экспериментальные установки «Ангара-5-1» и «Мир-М» являются уникальными, не имеющими аналогов в мире, сравнение результатов данного исследования с результатами других авторов затруднено. Есть несколько работ, посвященных исследованию биологических эффектов при использовании фотонного пучка ультравысокой мощности $[6,7,16]$, и в этих работах не анализируются варианты гибели клеток при воздействии гамма-излучением сверхвысокой мощности, а только приводятся данные об общей гибели клеток или сопоставляется противоопухолевая активность на животных.

Исследование зависимости индукции апоптоза лимфоцитов периферической крови здоровых доноров с использованием высокоинтенсивного тормозного излучения на установках «Ангара-5-1» и «Мир-М» в сравнении с гамма-излучением установки «Рокус-АМ» показало, что использование высокоинтенсивного излучения приводит $\mathrm{k}$ усилению индукции апоптоза. При этом рост уровня апоптоза линейный в диапазоне доз до 6 Гр и зависит от продолжительности инкубации после облучения (24 или 48 ч). В то же время имеются данные об отсутствии различий по уровню апоптоза при облучении дозами разной мощности [16]. Так, в работе Kotenko и соавт. показано, что при увеличении мощности дозы происходит рост числа двунитевых разрывов ДНК и нарушение механизмов ре- парации ДНК, но уровень апоптоза при этом не меняется. Аналогичные результаты получены в работе [17]. Но, хотя в этих исследованиях и изучали терапевтические диапазоны доз, возникает вопрос: почему нарушения репарации ДНК в сочетании с высоким уровнем двунитевых разрывов не приводили к усилению апоптотических процессов? Возможно, различия между нашим исследованием и этими работами объясняются особенностями биологических моделей. Так, если мы облучали мононуклеары периферической крови, то в исследованиях $[16,17]$ облучали фибробласты человека. К тому же облучение на установках «Ангара-5-1» и «Мир-М» отличается максимально высокой мощностью, порядка 100 МГр/с, что также может существенно влиять на результаты. И, возможно, при достижении таких мощностей доз перестают работать дополнительные системы репарации ДНК, которые проявляют активность при дозах 1-400 мГр/мин (0,017-6,7 МГр/с) [17]. Можно предположить, что в этом случае двунитевые разрывы ДНК имеют такую пространственную конфигурацию, что работа систем репарации оказывается затруднена (например, увеличивается «плотность» двойных разрывов). Следует также подчеркнуть, что радиочувствительность клетки зависит от фазы клеточного цикла и она минимальна для неделящихся клеток, к которым относятся мононуклеары периферической крови, большая часть которых - это лимфоциты. Именно неделящиеся клетки опухоли образуют наиболее радиорезистентную клеточную
А Ранний Апоптоз_МИР-М_лимфоциты_07_2017 9v*24с
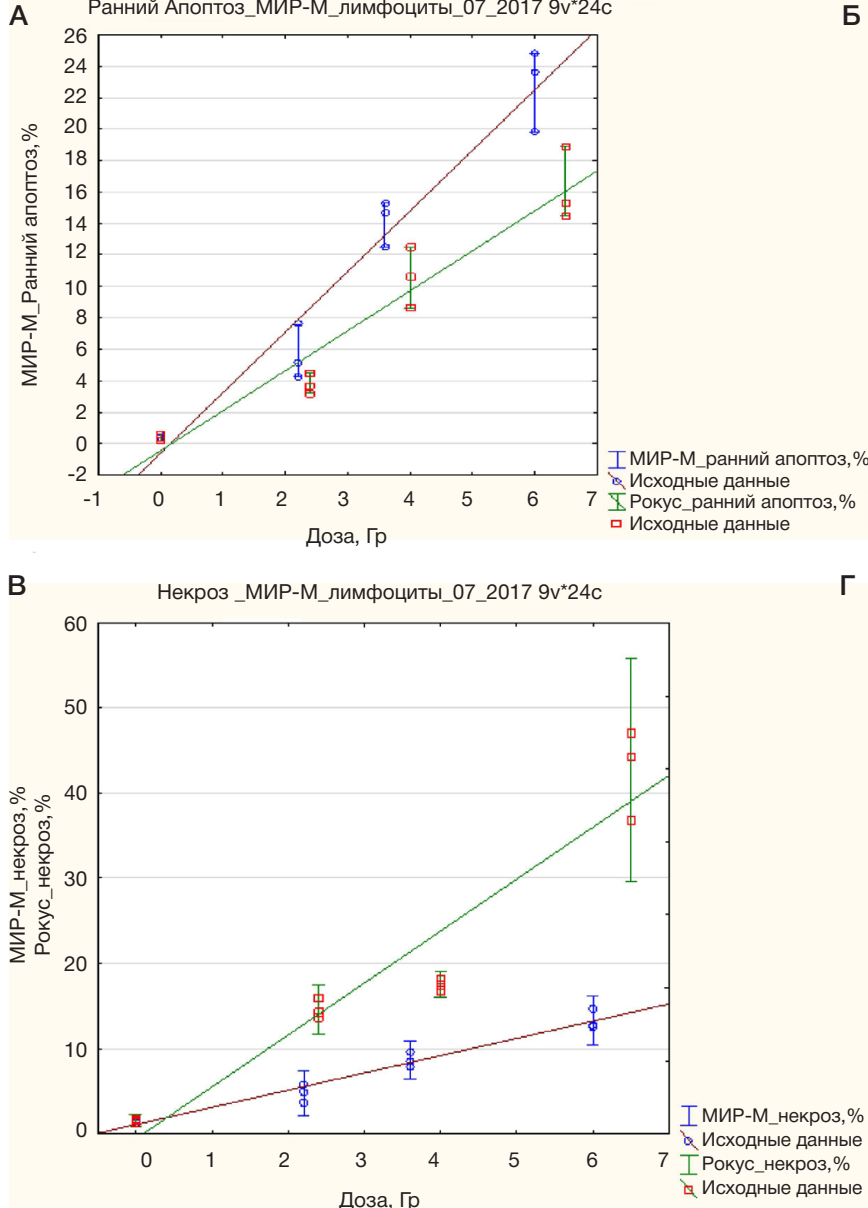

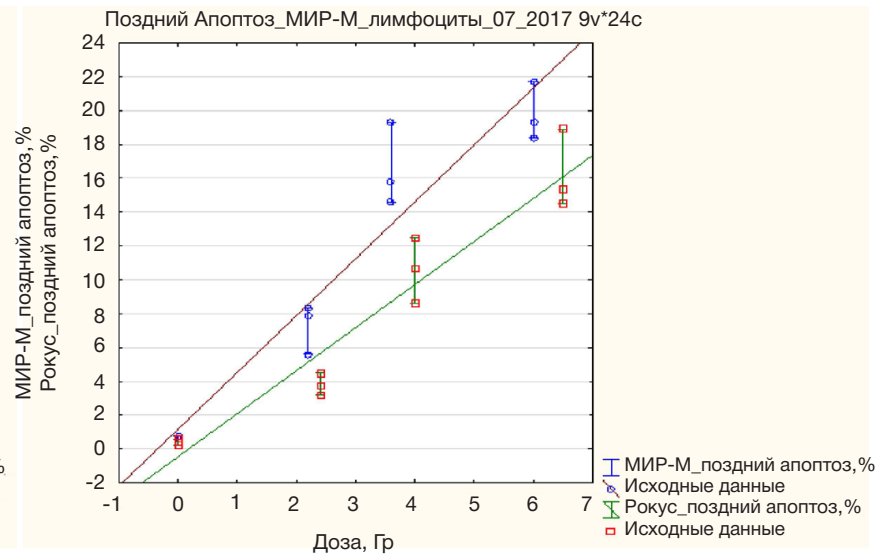

Суммарная гибель клеток_лимфоциты_07_2017 9v²4c

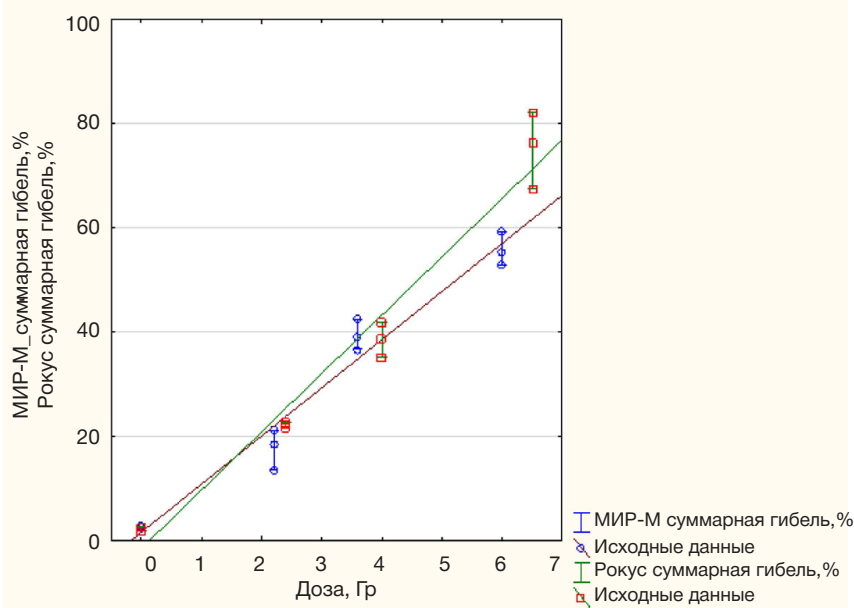

Рис. 4. Сравнение эффектов воздействия облучением экспериментальной установки «Мир-М», представляющей собой сильноточный наносекундный ускоритель электронов, и гамма-терапевтической установки «Рокус-АМ» на образцы суспензии лимфоцитов периферической крови человека в дозах от 0 до 6 Гр. (А) Изменение уровня раннего апоптоза (Annexin $\mathrm{V}+/ \mathrm{Pl}-$ ); (Б) изменение уровня позднего апоптоза (Annexin $\mathrm{V}+/ \mathrm{PI}+)$; (B) изменение уровня некроза (Annexin V-/PI+); (Г) суммарная клеточная гибель. Annexin V - аннексин V, PI — йодид пропидия. Знаками + и - указано присутствие или отсутствие окрашивания 
фракцию опухолевой клеточной популяции. Поэтому полученные нами результаты могут представлять определенный интерес для разработки методов лучевой терапии с использованием гамма-излучения, имеющего сврехвысокую мощность дозы.

Мы также обнаружили, что уровень некроза, индуцируемого высокоинтенсивным излучением, достоверно ниже такового, регистрируемого при использовании «терапевтического» гамма-излучения. При этом в диапазоне доз до 6 Гр уровень некроза возрастает пропорционально увеличению дозы. Анализ суммарной гибели клеток (лимфоцитов периферической крови) показал, что при использовании 2 мощностей дозы при однократном облучении в диапазоне доз до 6 Гр значение этого показателя примерно одинаково для установок разных типов Перечисленные результаты согласуются с тем, что наблюдали другие исследователи. Например, в работе Brüchne и соавт. [9] эффект задержки роста опухолевого узла КНТ-С фибросаркомы мышей был сопоставим при облучении на терапевтической гамма-установке и экспериментальной установке лазерного высокоинтенсивного излучения.

\section{Литература}

1. Mendelsohn J, Howley PM, Israel MA, Liotta LA et al, editors. The molecular Basis of Cancer. 2nd ed. Philadelphia: Saunders; 2001. p. 423-5.

2. Bessler H, Bergman M, Salman H, Cohen AM, Fenig E, Djaldetti M Factor(s) released from irradiated B-CLL cells induce apoptosis in leukemia lymphocytes. Cancer Lett. 2002 May 8; 179 (1): 103-8.

3. Ward JF. DNA damage produced by ionizing radiation in mammalian cells: identities, mechanisms of formation, and reparability. Prog Nucleic Acid Res Mol Biol. 1988; 35: 95-125.

4. Thompson CB. Apoptosis in patogenesis and treatment of disease. Science. 1995 Mar 10; 267 (5203): 1456-62.

5. Голдобенко Г. В., Костылев В. А. Актуальные проблемы радиационной онкологии и пути их решения. М.: АМФ-Пресс; 1994. с. 37.

6. Kroemer G, Reed JC. Mitochondrial control of cell death. Nat Med. 2000 May; 6 (5): 513-9.

7. Волкова М. А., Ширин А. Д., Османов Д. Ш., Френкель М. А. Возможности современной терапии острого промиелоцитарного лейкоза. Современная онкология. 2001; 3 (2): 1-9.

8. Альбиков 3. А., Велихов Е. П., Веретенников А. И. и др. Импульсный термоядерный комплекс Ангара-5-1. Атомная энергия. 1990; 68 (1): 26-35.

9. Brüchner K, Beyreuther E, Baumann M, Krause M, Oppelt M Pawelke J. Establishment of a small animal tumour model for in vivo studies with low energy laser accelerated particles. Radiat Oncol. 2014; 9: 57. DOI: 10.1186/1748-717X-9-57.

10. Konopacka M, Rogoliński J, Sochanik A, Slosarek K. Can high dose rates used in cancer radiotherapy change therapeutic effectiveness? Contemp Oncol (Pozn). 2016; 20 (6): 449-52. DOI: 10.5114/wo.2016.65603.

11. Ślosarek K, Konopacka M, Rogoliński J, Latocha M, Sochanik A. Effect of depth on radiation-induced cell damage in a water phantom. Rep Pract Oncol Radiother. 2005; 10 (1): 37-41. DOl: 10.1016/S1507-1367(05)71080-4.

12. Ślosarek K, Konopacka M, Rogoliński J, Sochanik A. Effect of dose-rate and irradiation geometry on the biological response of normal cells and cancer cells under radiotherapeutic conditions. Mutat Res Genet Toxicol Environ Mutagen. 2014 Oct; 773: 14-

\section{ВЫВОДЫ}

В диапазоне доз до 6 Гр уровень суммарной клеточной гибели при воздействии высокоинтенсивным гамма-излучением сопоставим с таковым при воздействии гамма-излучением терапевтической установки. При этом высокоинтенсивное излучение индуцирует клеточную гибель по пути апоптоза, в то время как низкоинтенсивное — по пути некроза.

Полученные нами результаты позволяют предположить, что высокоинтенсивное излучение может быть предпочтительнее низкоинтенсивного в клинической (онкологической) практике, т. к. индукция гибели значительной доли клеток по пути именно апоптоза более «физиологична» и должна реже приводить к осложнениям, связанным с массовой некротической гибелью клеток (распад тканей, интоксикация, повреждение нормальных тканей и др.). Необходимы эксперименты по исследованию механизмов активации апоптоза в неделящихся (интерфазных) клетках при использовании сверхвысоких мощностей дозы, в том числе в сравнении с клетками, находящихся в других фазах клеточного цикла

22. DOI: 10.1016/j.mrgentox.2014.07.005.

13. Wang Z, Zhao Z, Lu J, Chen Z, Mao A, Teng G et al. A comparison of the biological effect of $125 \mathrm{~J}$ seeds continuous low-dose-rate radiation and $60 \mathrm{Co}$ high-dose-rate gamma radiation on non-small cell lung cancer cells. PLoS One. 2015; 10 (8): e0133728. DOI: 10.1371/journal.pone.0133728.

14. Brehwens K, Bajinskis A, Haghdoost S, Wojcik A. Micronucleus frequencies and clonogenic cell survival in TK6 cells exposed to changing dose rates under controlled temperature conditions. Int J Radiat Biol. 2014 Mar; 90 (3): 241-7. DOl: 10.3109/09553002.2014.873831.

15. Zlobinskaya O, Siebenwirth C, Greubel C, Hable V, Hertenberger R, Humble N et al. The Effects of Ultra-High Dose Rate Proton Irradiation on Growth Delay in the Treatment of Human Tumor Xenografts in Nude Mice. Radiat Res. 2014 Feb; 181 (2): 177-83. DOI: 10.1667/RR13464.1.

16. Kotenko KV, Bushmanov AY, Ozerov IV, Guryev DV, Anchishkina NA, Smetanina NM et al. Changes in the number of double-strand DNA breaks in chinese Hamster V79 cells exposed to gamma-radiation with different dose rates. Int J Mol Sci. 2013 Jul 1; 14 (7): 13719-26. DOI: 10.3390/ijms140713719.

17. Озеров И. В., Осипов А. Н. Кинетическая модель репарации двунитевых разрывов ДНК в первичных фибробластах человека при действии редкоионизирующего излучения с различной мощностью дозы. Компьютерные исследования и моделирование. 2015; 7 (1): 159-176.

18. Кулинич Т. М., Боженко В. К., Сергеев И. Е., Сотников В. М., Хмелевский Е. В., Шишкин А. М. Изучение краткосрочных эфффектов воздействия ионизирующего излучения на лимфоциты периферической крови больных неходжкинскими лимфомами in vitro. Вестник Российского университета дружбы народов. Серия: Медицина. 2005; (1): 34-40.

19. Быков Ю. А., Крастелев Е. Г., Попов Г. В., Седин А. А., Федущак В. Ф. Субмикросекундный линейный импульсный трансформатор на напряжение 800 KВ с модульной малоиндуктивной системой первичного электропитания. Ядерная физика и инжиниринг. 2015; 6 (11-12): 579-86. DOI: 10.1134/ S2079562915060068.

\section{References}

1. Mendelsohn J, Howley PM, Israel MA, Liotta LA et al, editors. The molecular Basis of Cancer. 2nd ed. Philadelphia: Saunders; 2001.

p. 423-5.

2. Bessler H, Bergman M, Salman H, Cohen AM, Fenig E, Djaldetti M. 
Factor(s) released from irradiated B-CLL cells induce apoptosis in leukemia lymphocytes. Cancer Lett. 2002 May 8; 179 (1): 103-8.

3. Ward JF. DNA damage produced by ionizing radiation in mammalian cells: identities, mechanisms of formation, and reparability. Prog Nucleic Acid Res Mol Biol. 1988; 35: 95-125.

4. Thompson CB. Apoptosis in patogenesis and treatment of disease. Science. 1995 Mar 10; 267 (5203): 1456-62.

5. Goldobenko GV, Kostylev VA. Aktual'nye problemy radiatsionnoy onkologii i puti ikh resheniya. Moscow: AMF-Press; 1994. p. 37. Russian.

6. Kroemer G, Reed JC. Mitochondrial control of cell death. Nat Med. 2000 May; 6 (5): 513-9.

7. Volkova MA, Shirin AD, Osmanov DSh, Frenkel MA. Vozmozhnosti sovremennoy terapii ostrogo promielotsitarnogo leykoza. Sovremennaya onkologiya. 2001; 3 (2): 1-9. Russian.

8. Albikov ZA, Velikhov EP, Veretennikov Al et al. Impul'snyy termoyadernyy kompleks Angara-5-1. Atomnaya energiya. 1990; 68 (1): 26-35. Russian.

9. Brüchner K, Beyreuther E, Baumann M, Krause M, Oppelt M, Pawelke J. Establishment of a small animal tumour model for in vivo studies with low energy laser accelerated particles. Radiat Oncol. 2014; 9: 57. DOI: 10.1186/1748-717X-9-57.

10. Konopacka M, Rogoliński J, Sochanik A, Slosarek K. Can high dose rates used in cancer radiotherapy change therapeutic effectiveness? Contemp Oncol (Pozn). 2016; 20 (6): 449-52. DOI: 10.5114/wo.2016.65603.

11. Ślosarek K, Konopacka M, Rogoliński J, Latocha M, Sochanik A. Effect of depth on radiation-induced cell damage in a water phantom. Rep Pract Oncol Radiother. 2005; 10 (1): 37-41. DOI: 10.1016/S1507-1367(05)71080-4.

12. Ślosarek K, Konopacka M, Rogoliński J, Sochanik A. Effect of dose-rate and irradiation geometry on the biological response of normal cells and cancer cells under radiotherapeutic conditions. Mutat Res Genet Toxicol Environ Mutagen. 2014 Oct; 773: 1422. DOI: 10.1016/j.mrgentox.2014.07.005.
13. Wang Z, Zhao Z, Lu J, Chen Z, Mao A, Teng G et al. A comparison of the biological effect of $125 \mathrm{~J}$ seeds continuous low-dose-rate radiation and $60 \mathrm{Co}$ high-dose-rate gamma radiation on non-small cell lung cancer cells. PLoS One. 2015; 10 (8): e0133728. DOl: 10.1371/journal.pone.0133728.

14. Brehwens K, Bajinskis A, Haghdoost S, Wojcik A. Micronucleus frequencies and clonogenic cell survival in TK6 cells exposed to changing dose rates under controlled temperature conditions. Int J Radiat Biol. 2014 Mar; 90 (3): 241-7. DOI: 10.3109/09553002.2014.873831.

15. Zlobinskaya O, Siebenwirth C, Greubel C, Hable V, Hertenberger R, Humble $\mathrm{N}$ et al. The Effects of Ultra-High Dose Rate Proton Irradiation on Growth Delay in the Treatment of Human Tumor Xenografts in Nude Mice. Radiat Res. 2014 Feb; 181 (2): 177-83. DOI: 10.1667/RR13464.1.

16. Kotenko KV, Bushmanov AY, Ozerov IV, Guryev DV, Anchishkina NA, Smetanina NM et al. Changes in the number of double-strand DNA breaks in chinese Hamster V79 cells exposed to gamma-radiation with different dose rates. Int J Mol Sci. 2013 Jul 1; 14 (7): 13719-26. DOI: 10.3390/ijms140713719.

17. Ozerov IV, Osipov AN. [Kinetic model of DNA double-strand break repair in primary human fibroblasts exposed to low-LET irradiation with various dose rates]. Computer Research and Modeling. 2015; 7 (1): 159-76. Russian.

18. Kulinich TM, Bozhenko VK, Sergeev IE, Sotnikov VM, Khmelevsky EV, Shishkin AM. [Investigation of short term effects of y-irradiation on peripheral blood lymphocytes of non-hodgkin malignant lymphoma patients]. RUDN Journal of Medicine. 2005; (1): 34-40. Russian.

19. Bykov YuA, Krastelev EG, Popov GV, Sedin AA, Fedushchak VF. Submikrosekundnyy lineynyy impul'snyy transformator na napryazhenie 800 KV s modul'noy maloinduktivnoy sistemoy pervichnogo elektropitaniya. Yadernaya fizika i inzhiniring. 2015; 6 (11-12): 579-86. DOI: 10.1134/S2079562915060068. Russian. 